Published on Reviews in History (https://reviews.history.ac.uk)

\title{
Prisoners of War Review Article
}

Review Number: 2295

Publish date: Thursday, 29 November, 2018

Author: Clare Makepeace

ISBN: 978-1107145870

Date of Publication: 2017

Price: $£ 25.20$

Pages: 304pp.

Publisher: Cambridge University Press

Publisher url: https://www.cambridge.org/core/books/captives-of-war/B438B3315433212AA001E6DCE9084F98

Place of Publication: Cambridge

Author: Lizzie Oliver

ISBN: 978-1350024120

Date of Publication: 2017

Price: $£ 71.89$

Pages: 208pp.

Publisher: Bloomsbury Academic

Publisher url: https://www.bloomsbury.com/uk/prisoners-of-the-sumatra-railway-9781350024144/

Place of Publication: London

Reviewer: Alan Malpass

The fate of prisoners of war (POWs) is now established within the mainstream of historical enquiry. As well as a growing literature on the subject, modules dedicated to studying the history of POWs are now a common feature on university history courses. The two books under review focus on British servicemen captured during the Second World War. Moving beyond studies of diplomatic relations between belligerents attempting to safeguard their POWs in enemy hands and examinations of material conditions within the camps, they explore how British POWs attempted to comprehend, record and communicate their experiences during and after captivity.

142,319 men serving in the UK armed forces were captured by Italian and German forces during the 193945 conflict. The question at the heart of Captives of War: British Prisoners of War in Europe in the Second World War by Clare Makepeace is: 'how [...] did British POWs make sense of their wartime imprisonment?' Adopting a cultural approach, the study 'reaches into their interior and intimate worlds, to look at how they mentally and emotionally responded to their wartime imprisonment' (p. 5), paying particular attention to how British POWs 'made sense of their experiences as men' (p. 7, original emphasis). To delve into this emotional world, Makepeace draws upon personal narratives composed by POWs during their captivity including, 40 diaries, 25 logbooks (small notepads used like a scrapbook), and 26 sets of correspondence, all of which is catalogued in an appendix outlining the details of each man. Her analysis of these sources is holistic in that they are not only viewed as records of captivity, but also part of how the experiences documented within them were shaped. This is a study not only of words but also of the illustrations and assorted paraphernalia created and collected by the men. Makepeace focuses on personal narratives composed during captivity rather than memoirs and oral-history, arguing that what was important 
to note and reflect on at the time might not be considered significant to dwell on forty years' later (p. 23).

Chapter one focuses on capture, examining how British POWs recorded and represented their transition from combatant to captive. When reflecting on their capture, POWs 'wanted to impress on their readers that they bore no responsibility for their fate' (p. 39). They portrayed themselves as helpless, unable to avoid surrendering due to factors beyond their control and emphasised they had never contemplated being a POW. Contrary to the 'stigma of surrender' that POWs, including British captives, expressed during the Great War, Makepeace find that feelings of emasculation and guilt are rare among British POWs writing about their capture during the Second World War.(1) At the same time, the need to explain the circumstances of their capture suggests an 'unconscious awareness' that their capture might be perceived by others as dishonourable (p. 40). Retrospectively POWs would consider their capture to be a transformative point in their life, but to focus on surrender as the pivotal moment 'is to misunderstand the mentality of British servicemen'. Noting that these men were 'remarkably optimistic' that their liberation after an Allied victory was imminent, Makepeace highlights that British POWs were preoccupied with homecoming from the outset of their indefinite durance and she returns to this theme throughout the book (p. 52).

Chapter two examines how POWs responded to being held captive and the inimitable aspects of incarceration. POWs continued to contribute to the war effort from inside the camp, the first section discussing the acts of defiance and rebellion that 'were key in giving meaning to their existence' (p. 56). The chapter goes on to explore how POWs undermined the captor-captive relationship by portraying themselves as equal or superior to their enemies. Italians, in particular, were regarded as inferior. POWs were insulted by the idea that they had been captured by Italians, who they thought of as poor soldiers, rather than Germans. In their personal narratives, POWs depicted themselves as leading 'normal' lives, following daily routines and participating in sporting, educational and leisurely activities within the camp. They also wrote of their achievements, compiling lists of books read and discussing their contribution to camp theatre productions. Simultaneously, their writings emphasised the unique aspects of their lives, namely the quantity of food they received and the unfamiliar surroundings of the camp. POWs created a new vocabulary to describe aspects of their experience. For instance, 'To bash' meant 'to eat up in one go' (p. 79). Here, Makepeace suggests that British POWs were constructing a 'Kriegie identity' opposed to people outside the camp who could not understand their experiences (p. 77). She also questions the 'upbeat image' of captivity depicted in personal narratives and explores feelings of emasculation. Time spent behind barbed wire was sometimes thought of as wasted, captivity being considered a worthless experience that could never be successfully understood by the outside world.

Chapter three examines how POWs dealt with their homosocial environment. It first considers the friendships, or lack of them, that were forged in captivity and how bonding between POWs was unsurprisingly strained within the milieu of the camp. Makepeace identifies three factors which influenced relationships between POWs: 'date of capture, rank, and allocation of food' (p. 127). Collective hardships, namely the length of time behind barbed wire and the lack of food, 'failed to instil group solidarity' (p. 94). The chapter also discusses female impersonators and their performances in theatrical productions, illuminating the contradictory attitudes towards heterosexual and homoerotic yearning. On the one hand, 'admiration for men in drag could be used to exert collective male superiority' (p. 127). Impersonators were often described as making better women than women themselves. On the other, when performances continued beyond the stage, the boundaries of sexuality were blurred. What Makepeace suggests is that male sexuality, not only in the camp but in mid-20th century Britain generally, was far more fluid than today.

Chapter four, 'Ties with home', explores how POWs made sense of captivity through their relationships with family and loved ones. Letters and parcels passed through the barbed wire provided a physical connection with home. The value POWs invested in letters lay in what they embodied as objects. As Makepeace explains, 'they bridged the hundreds of miles lying between them and home, enabling mothers, wives and sweethearts to join these men in captivity' (p. 130). Letters were spiritual nourishment, making captivity more bearable. The chapter also examines the imaginative world of British POWs, who returned home in their daydreams, a ritual usually saved for Sundays. Connections with home were a source of 
strength yet, the hope of an imminent homecoming made it difficult for the men to adjust to captivity. Makepeace demonstrates that while feelings of closeness with home provided POWs with emotional strength, fantasising about homecoming reminded the men that they were separated from their loved ones, unable to fulfil their roles as 'provider, protector and procreator' (p. 153).

Chapter five examines what it meant to 'go round the bend', an old Navy phrase adopted by POWs to describe 'how their minds became disturbed during captivity' (p. 154). It provides an overview of the conflicting research into 'barbed-wire disease' during the First World War and the ambiguity surrounding the diagnosis of psychological disturbances brought about by imprisonment. POWs' narratives clearly demonstrate how they suffered, experienced, and witnessed psychological disturbances brought about by imprisonment. Often difficult to describe, Makepeace examines the pictures and sketches that POWs include in their personal narratives which help reveal their feelings much more than words. Makepeace identifies three conditions in camp life which the POWs identified as responsible for psychological disturbances: the presence of barbed-wire, which caused 'wire-itis', the difficulty in escaping other POWs, and the monotony of captivity which was filled with 'empty-time' (pp. 163-4). The chapter discusses the differing theorisations of four imprisoned British medical officers who, despite conflicting interpretations, all agreed that as time in captivity wore on no POW would remain unaffected (p. 171). Despite the stigma attached to metal illness, POWs were 'remarkably frank' discussing the issue. Makepeace suggests that by discussing their mental state POWs conveyed the hardships they faced behind barbed wire (pp. 172-3). The chapter goes on to discuss the potential courses of action that could be taken by POWs that were diagnosed.

The final months of the war and the reaction of POWs to their eventual liberation is the concern of chapter six. After the success of D-Day the lives of British POWs descended into chaos. Food parcels were dramatically reduced as were local food and fuel supplies to camps which soon became overcrowded with the influx of captured US servicemen. Red Cross reports noted the dangerously inadequate supplies, with conditions considered satisfactory in only a third of camps. The POWs involved in the Long March from camps in the East to those in the West suffered the greatest hardship, marching 12-18 miles a day in bad weather, with little food and the threat of allied bombing. Makepeace notices a change in the form personal narratives took during this phase of captivity with POWs switching from diaries to logbooks, or vice versa, indicating that they viewed this phase of captivity as noteworthy. She notes that 'articulations of relief, jubilation or excitement, which might be expected from men who had spent years of the war in captivity, are conspicuously absent' (p. 187). But the format of entries, with phrases such as 'FREE', 'LIBERATED' and 'RECAPTURED' reveal their feelings. Allied captives - the majority being recaptured in the west - freed from European camps were repatriated swiftly. The process was completed by the end of May 1945, although some POWs complained of the slowness of return. POWs ended their personal narratives at various points during this time. Liberation often meant the termination of these accounts, while others wrote their final entry when arriving in the UK or when they were reunited with their loved ones.

Given what is revealed in the preceding chapters, Makepeace argues that 'it is most unlikely that any POW, at an emotional level, was able to leave behind his captivity experience upon arrival back to Britain' (p. 192). Chapter seven examines the 'Resettling' of POWs. As personal narratives were ended shortly after liberation or arrival to Britain, Makepeace draws upon medical papers and psychiatric reports during and after war to examine the issues ex-POWs faced. The need to provide resources and support to returning POWs was discussed during the conflict. Ex-POWs of the First World War shared their experiences with officials, describing how they never fully recovered from their captivity. With little state support, many exPOWs, they explained, were unemployed or had turned to crime, a large proportion never reintegrating into civilian life. The chapter surveys the various ideas for helping returned POWs which were put forward and often met with contrary opinions. Makepeace provides detail on the work of the Civilian Resettlement Units, concluding that they had a positive effect on those that attended. At the same time, there was a clear lack of understanding of how captivity had affected POWs among officials and the POWs themselves. It is therefore difficult to present an accurate picture of the extent of distress among ex-POWs and how successfully it was treated. Captives of War ends in the late 1940s. 'One area ripe for further research', Makepeace suggests, 'is how the POW experience has been remembered in post-war society' (p. 229). This is a major theme of the 
second book under review, though in the context of Far Eastern captivity.

In Prisoners of the Sumatra Railway, Lizzie Oliver examines the experiences and memory of British POWs held on the titular island located in western Indonesia. In a similar vein to Captives of War, Oliver's aim is to 'explore the ways in which former POWs have represented their experiences through different life-writing genres' (p. 3). The significant difference between the two books, apart from geographical focus, is that Oliver examines memory, exploring 'the responses to the history of Far Eastern captivity by second and third generations' (p. 3). Chapter one provides background information on the construction of the Sumatra Railway, which ran just under 140 miles through thick jungle and mountainous terrain, linking western and eastern ports on the island. It outlines the capture of the island in March 1942, and the perilous transportation of POWs to it, as well as providing insight into the camps erected along the railway and the work performed by Allied POWs. Oliver compares the conditions on the Sumatra Railway to the Burma-Thailand line, discussing the health of the captives and mortality rates. Despite being shorter than the latter railway, the Sumatra railway took nearly the same time to complete due to the more unforgiving terrain and the fact that the POWs, the first being set to work on the line in May 1944, were already malnourished and weakened from two years of forced labour in other regions of the Far East. A total of 4,968 Allied POWs were employed on the Sumatra Railway, including 1,066 British, Australian and New Zealand servicemen (p. 29). Prior to their arrival, hundreds of thousands of indigenous slave labourers known as 'Romushas' (the Japanese term for 'coolie') had begun preparing the foundations of the railway; a short section details their horrific working conditions, non-existent support networks, and difficulties after the war. The chapter also considers why Sumatra has not formed part of the collective memory of Far Eastern captivity, discussing the lack of wartime reports concerning Sumatra and the post-war censoring of atrocity stories.

Chapter two examines the life-writing adopted by POWs during and after captivity. Diaries among Far Eastern POWs are rare and Oliver has only uncovered two written by POWs directly working on the Sumatra Railway. As she explains, this is not due to a 'lack of will' among the POWs to detail their experiences but the restrictive conditions in which they could write. In contrast to European camps, letters and postcards were not regularly received or sent by POWs on Sumatra. Paper was a valuable commodity which could be traded for extra food and resources, 'or roll precious cigarettes', rather than record experiences (p. 38). Furthermore, diaries had to be kept secret as their discovery would be severely punished. Oliver describes the 'mini-memoir' genre of life-writing, which were entries of several paragraphs recapping several months in captivity. Similar to Makepeace's finding that POWs in Europe were optimistic of an imminent homecoming, Oliver suggests that POWs believed that liberation was only a few months away, a hope which sustained them during their captivity (p. 51). The chapter goes on to consider the authorising of POW memoirs and common features within memoirs written by ex-Sumatra POWs. Finally, echoing Makepeace's analysis of the imaginative world of British POWs in Europe, Oliver discusses the maintenance of 'imaginary libraries'. While escape was impossible, 'it was essential for POWs to use their imaginations to breach their borders figuratively' (p. 57).

Chapter three focuses on the 'linguistic features' of POW life-writing. The chapter begins by noting the official instructions issued to POWs returning from the Far East after liberation to 'guard their tongue' (p. 67). Ex-POWs were cautioned against publicising their experience and discussing it with loved ones, arguing that it would only serve to distress them. Clearly, they were able to tell their stories eventually and therefore this chapter does not explore the struggles in telling stories, but rather the specific challenges POWs faced in communicating them. The nature of the camp system along the railway meant that a range of languages were spoken: Malay, English, Japanese and Dutch as well as dialects of Chinese and Tamil (p. 68). Language learning was key to survival and POW life-writings often include lists of translations. For example, the Japanese term Speedo meant 'to work faster and harder' (p. 72). Grammar, Oliver explains, was not essential in communication and the POWs instead 'stringed together' words into sentences and alternated between different languages within the same conversation, a process called 'code-switching' ( $\mathrm{p}$. 74). The chapter goes on to examine how the Japanese enforced their language on POWs 'as a tool to subjugate' them. It was imperative that British POWs learned phrases quickly as innocent mistakes could be met with severe beatings (pp. 75-6). Oliver explores how the enforcement of language also opened a space 
of linguistic resistance and how POWs adopted certain languages in certain contexts. Humour was another important method of resistance. POWs belittled individual guards, lampooning Japanese and Korean stereotypes and designating them nicknames which denoted characteristics which dehumanised them. (p. 77). Oliver singles out 'Kongsi' as a particularly important and untranslatable phrase in the life-writing of Far Eastern POWs. Kongsi, she explains, 'referred to a small group of two or three men who helped each other survive through the monotony of POWs life' (p. 79). Members of the Kongsi provided each other daily support, sharing food and resources and caring for those that fell ill, although such arrangements did not always work out. Finally, the chapter examines the role of the camp interpreter in mediating between POWs and their captors.

Chapters four and five move beyond Sumatra, analysing the post-war narrative of the Far Eastern Prisoner of War (FEPOW). 'The degradation of the human body', Oliver notes, is a prevalent theme in the life-writing of FEPOWs. Chapter four summarises the work of three British Medical Officers on the Sumatra Railway. Working against a severe lack of food and medical supplies, their work 'made a striking impact on the memoirs of the men who experienced the camps there' (p. 89). The efforts of artists who attempted to record the illness and disease they witnessed are also examined. Oliver makes clear the difficulty POWs had in representing the physical suffering they experienced, exploring how POWs viewed their gradual starvation and the brutalisation of their bodies as well as the reaction of loved ones to the effects of captivity after repatriation. Assaults upon the skin were incessant and, focusing on the life of one ex-POW of Sumatra, Oliver explores how 'his skin became [...] a 'parchment' for his family to read' (p. 104).

POWs on Sumatra were discovered by Allied forces in early September 1945 and were immediately identified as requiring urgent medical treatment. The final chapter of Prisoners of the Sumatra Railway examines the creation and legacy of the FEPOW, situating the narratives of the Sumatra Railway within the broader story of Far Eastern captivity. Like Makepeace, Oliver notes that POWs end their life-writing during the voyage home, when reunited with loved ones or when demobbed. While they present their story as finished, closing that chapter of their life, Oliver discusses how this was far from true. FEPOWs continued to suffer from depression, loneliness, isolation and guilt which could result in suicide, accidental death, and other physical and mental wounds. Oliver assesses the work of the Civil Resettlement Units, and why they were not as appealing to FEPOWs compared to their European counterparts. The chapter explores how stories of captivity in the Far East were communicated during the claim for compensation from the Japanese government. The image of the FEPOW was created during the campaign for compensation organised by the Returned British Prisoners of War Association. In the pages of The Clarion, the associations newsletter, the differences in European and Far Eastern captivity were highlighted. Submissions from Far Eastern POWs quickly dominated content, causing dissatisfaction among ex-POWs from European camps. Factions soon developed with FEPOWs creating separate local clubs, more than 60 of which were established by 1951. Challenging the prevailing assumption that FEPOWs were reluctant to speak of their experiences, Oliver contends that they did but 'chose to do so more commonly in public rather than domestic spaces' (p. 116). Drawing on the theory of 'post-memory', the chapter goes on to explore how second and third generations of FEPOWs learned about their fathers and grandfathers experiences. The chapter includes an analysis of the post-war exhibition of Charles Thrale an ex-POW who spent time on the Burma-Siam Railway, Changi and Singapore. Examining the entries recorded in visitor books, Oliver argues that the second generation 'were already attempting to understand the history and impact of their fathers' captivity' in the immediate post-war (p. 122).

Despite the geographical and chronological differences between the two studies, the approaches and findings of Captives of War and Prisoners of the Sumatra Railway complement one another, indeed Oliver draws upon Makepeace's earlier work on POW correspondence in her book. Focusing on the personal narratives and life writing of British POWs during and after the Second World War, they open up the emotional world of the captives examining how they attempted to make sense of their experiences and represent them to their loved ones and British society. In addition to the optimistic expectation that liberation was imminent, Makepeace and Oliver both highlight the importance of imagination and creativity to emotional and mental survival of British POWs. Bonding was also key, although relationships were predictably strained by the 
confined environment POWs existed in. POWs in Europe and the Far East were clearly aware of their unique situation and both groups adopted specific languages to describe unique aspects of their lives, all the time fearful that they would be unable to effectively communicate their experiences to the outside world. Despite these similarities, both authors acknowledge the hardships and suffering of POWs in the Far East were radically different to those in Europe. In their discussions of post-war support for ex-POWs, Olive and Makepeace highlight that the fundamental differences between experiences in Europe and the Far East were not lost on the POWs themselves, with the latter separating into separate organisations. This was not initially acknowledged in post-war Britain at a time when the effects of captivity on the ex-POWs was not really understood.

The objective both authors set themselves - an emotional history of British POWs - is ambitious, and as a result, there are parts of both books that beg for further development. For instance, Makepeace might have fleshed out her analysis of captor-captive relations in chapter two by considering broader British attitudes towards Italians and Germans, the former being considered a secondary adversary. For instance, British commanders were wary of encouraging the mocking attitude towards Italian soldiers fearing that their forces would become complacent against them in battle. Contrary to public perceptions, military intelligence reported that Italian soldiers were just as capable as their British counterparts, but poorly led and equipped. (2) One weakness of Captives in War, which is acknowledged by the author in the introduction, is that it is dominated by narratives written by officers. As they were exempt from working, the central theme in the experience of British POWs across Europe, employment, is by and large absent from the study. Whether or not joining working parties outside the camp provided a much needed escape or if arduous labour simply added to emotional and physical hardship is open to question.(3) In regards to Prisoners of the Sumatra Railway, the study is relatively short and by writing a history of the British life-writing specific to the railway as well as tackling the broader post-war memory of FEPOWs, Oliver's analysis is brief and a general conclusion is absent.

These, though, are minor criticisms which do not detract from the exceptional scholarship of the authors and the wealth of information contained within both books. It remains to be seen how far the themes covered in both works can be applied to other contexts including different Allied and Axis POWs and, perhaps, civilian internees. Brining the voices of British POWs to the fore, examining how they represented their experiences through various forms of personal narratives and life-writing, both Makepeace and Oliver provide original insight into the emotional worlds of these men. Well written and researched, these studies are testament to the continued strength of POW history. Furthermore, they clearly demonstrate how examinations of the POW experience can make important contributions to our understanding of $20^{\text {th }}$ century society and culture more broadly. They will be of great use and interest to scholars of life-writing, wartime imprisonment, and 20th-century British culture.

\section{Notes}

1. Brian K. Feltman, The Stigma of Surrender: German Prisoners, British Captors, and Manhood in the Great War and Beyond (North Carolina, 2015), p. 198.Back to (1)

2. Bob Moore, 'British Perceptions of Italian Prisoners of War, 1940-7', in Prisoners of War, Prisoners of Peace: Captivity, Homecoming and Memory in World War II, ed. Bob Moore and Barbara HatelyBroad (Oxford, 2005), pp. 27-8.Back to (2)

3. Simon Paul Mackenzie, The Colditz Myth: British and Commonwealth Prisoners of War in Nazi Germany, (Oxford, 2004), p. 193.

$\underline{\text { Back to (3) }}$ 


\section{Links}

[1] https://reviews.history.ac.uk/item/298311 [2] https://reviews.history.ac.uk/item/298312 